Functional

Ecology 2001

15, $722-731$

\title{
Photosynthetic adaptation and acclimation to exploit seasonal periods of direct irradiance in three temperate, deciduous-forest herbs
}

\author{
D. E. ROTHSTEIN $\dagger$ and D. R. ZAK \\ School of Natural Resources and Environment, University of Michigan, Ann Arbor, MI 48109-1115, USA
}

\begin{abstract}
Summary
1. We evaluated the potential for three species of deciduous-forest herbs to exploit seasonal periods of direct irradiance. In particular, we investigated the importance of photosynthetic acclimation as a mechanism for shade-tolerant herbs to utilize direct light reaching the forest floor before canopy expansion in the spring and after canopy leaf drop in the autumn.

2. We measured the photosynthetic and growth characteristics of three co-occurring herbs of a northern hardwood forest: the spring ephemeral Allium tricoccum Ait., the summer-green Viola pubescens Ait., and the semi-evergreen Tiarella cordifolia L.
\end{abstract}

3. Leaf $\mathrm{CO}_{2}$ exchange, leaf mass per area, and leaf biochemistry differed among species and seasonally within species to match the changing light environment below the forest canopy. From spring to summer, as irradiance dropped with the expansion of the overstorey canopy, Viola leaves exhibited reduction of both photosynthetic capacity and light compensation point. Weaker acclimation of less magnitude occurred in Tiarella leaves over the spring-summer light transition; this was followed by further acclimation to the stronger autumn irradiance.

4. Viola's greater range of photosynthetic acclimation was associated with shifts in allocation between Rubisco and chlorophyll, as well as changes in total leaf nitrogen (N) concentration and leaf mass per area (LMA). In contrast, Tiarella's narrow range of acclimation was associated solely with changes in allocation to Rubisco versus chlorophyll, with no changes in total leaf $\mathrm{N}$ or LMA.

5. Seasonal changes in leaf chemistry and structure in Viola suggest a stepwise ontogeny whereby individual leaves are able to function as 'sun leaves' for 3-5 weeks in the spring, and then as 'shade leaves' for up to 3 months in the summer.

6. Whole-plant biomass accumulation showed that all three species accumulated most of their annual biomass increment during periods of direct irradiance. These results demonstrate the importance of brief seasonal periods of strong irradiance to the growth of deciduous forest herbs, even shade-tolerant, summer and evergreen species.

Key-words: Photosynthesis, light relations, spring ephemeral, herbaceous, phenology

Functional Ecology (2001) 15, 722-731

\section{Introduction}

Seasonal changes in light availability on the floor of temperate deciduous forests are related to the dynamics of the overstorey canopy. Such changes present a unique set of challenges to the herbaceous plants growing in the understorey. These changes are characterized by the sharp reduction in irradiance from

$\dagger$ Author to whom correspondence should be addressed. Present address: Department of Forestry, Michigan State University, East Lansing, MI 48824-1222, USA. E-mail: rothste2@msu.edu spring to summer as the overstorey canopy develops, deep shade for most of the growing season, and then a gradual increase in irradiance from summer to autumn as the overstorey canopy senesces (Fig. 1). Two distinct strategies have been identified for coping with the deep shade cast by the overstorey canopy in summer: (i) avoidance - employed by spring ephemeral herbs that exploit the narrow window of full sun between snow-melt and canopy closure; and (ii) shade tolerance-employed by summer and evergreen species that have adapted to survive the long summer shade period (Hicks \& Chabot 1985). Spring ephemeral herbs exhibit typical 'sun-plant' photosynthetic 


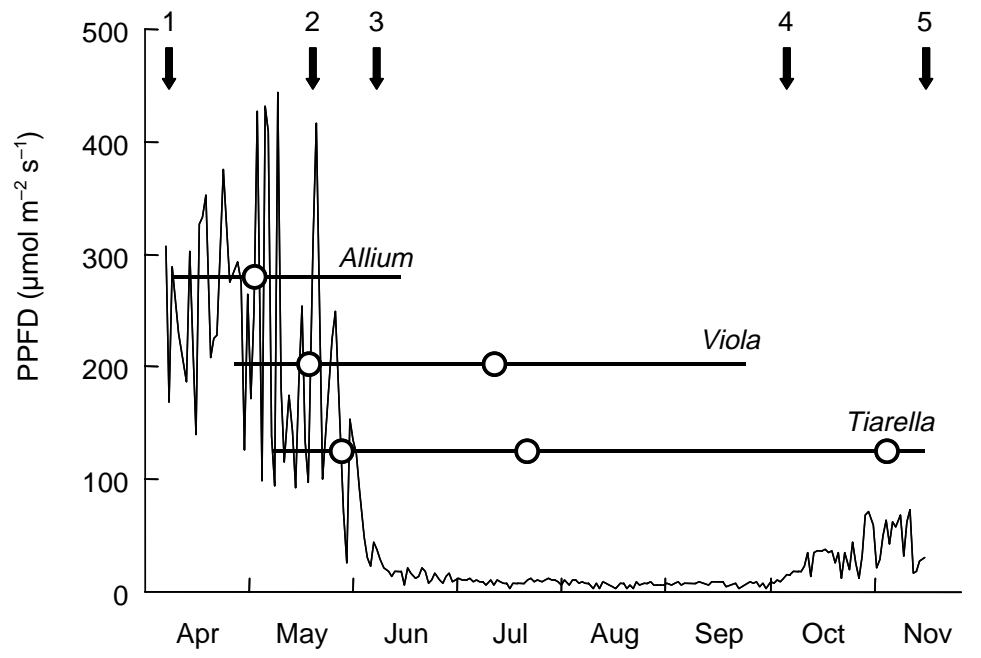

Fig. 1. Leaf phenology of Allium tricoccum, Viola pubescens and Tiarella cordifolia in relation to the average photosynthetic photon flux density (PPFD) reaching the forest floor each day of the snow-free year in 1997. The horizontal lines represent the period when each species has green leaves above-ground, and the circles represent dates at which physiological sampling was conducted on each species. The numbered arrows at the top represent the timing of the following events: (1) snow-melt; (2) beginning of canopy bud-break; (3) canopy at full leaf expansion; (4) beginning of canopy leaf senescence; and (5) first snow accumulation.

characteristics, having high light-saturated rates of photosynthesis $\left(A_{\max }\right)$ and light compensation points (LCP), whereas summer and evergreen species exhibit typical 'shade-plant' characteristics such as low $A_{\max }$ and LCP (Sparling 1967; Taylor \& Pearcy 1976).

Despite the obvious differences in life history and physiology between shade avoiders and shade tolerators, this distinction may not be so clear. Because leaves of many of the summer and evergreen species emerge prior to canopy closure in the spring (Sparling 1967), and leaves of evergreens persist after canopy senescence in the autumn, these periods of high irradiance may be important for the growth of shadetolerating species. In addition, there is evidence that some shade-tolerant species decrease their photosynthetic capacities from spring to summer (Graves 1990; Taylor \& Pearcy 1976) and, in the case of evergreens, increase photosynthetic capacity from summer to autumn (Skillman et al. 1996; Yoshie \& Kawano 1986). However, there are numerous studies that document no acclimation across the spring (Landhausser et al. 1997) or autumn (Landhausser et al. 1997; Oberhuber \& Bauer 1991; Pitelka \& Curtis 1986; Tissue et al. 1995) transitions in irradiance.

Even where photosynthetic acclimation has been demonstrated, it is not clear to what extent mechanisms of acclimation are shared between species or what range of acclimation is possible, nor is it clear how photosynthetic acclimation influences plant growth. Acclimation by summer and evergreen herbs suggests

(C) 2001 British Ecological Society, Functional Ecology, 15, 722-731 that the brief periods of high irradiance in the spring and autumn (for evergreens) may be quite important to the growth of these species. To address these issues, we investigated photosynthetic adaptation and acclimation in three deciduous forest herbs of contrasting life history. We were particularly interested in understanding the mechanisms behind adaptation and acclimation of each species, and in understanding their importance for exploiting brief, seasonal periods of high irradiance. We hypothesized that: (i) adaptation and acclimation would result in greater photosynthetic capacity in the spring and autumn; (ii) differences in photosynthetic capacity would be associated with differences in relative allocation to $\mathrm{CO}_{2}$ fixation versus lightharvesting components of photosynthesis; and (iii) the spring and autumn light phases should make a disproportionate contribution - relative to their duration - to biomass increment in all three species.

\section{Materials and methods}

\section{STUDY SITE, SPECIES AND SAMPLING PROTOCOL}

Our study was conducted in a single northern hardwood forest stand located in Wexford County, northern Lower Michigan $\left(44^{\circ} 20^{\prime} \mathrm{N}, 86^{\circ} 00^{\prime} \mathrm{W}\right)$, USA. This stand has been classified as belonging to the sugar maple-basswood/ Osmorhiza ecosystem type by Host \& Pregitzer (1991). This forest type is characterized by a diverse and abundant herbaceous community. We assigned the herbaceous species of this stand into one of the following three phenological groups, based on those of Mahall \& Bormann (1978): (i) spring ephemerals-species in which leaf development occurs at or before snow-melt and leaf senescence occurs during expansion of the forest canopy; (ii) summer greens - species in which leaf development occurs before expansion of the forest canopy and leaf senescence occurs before canopy leaf drop in the autumn; and (iii) semi-evergreens - species in which leaf development occurs during the expansion of the forest canopy and leaf senescence occurs the following spring after snow-melt. We chose one representative species from each group for physiological study: the spring ephemeral Allium tricoccum Ait., Liliaceae (hereafter referred to as Allium), the summergreen Viola pubescens Ait., Violaceae (Viola), and the semi-evergreen Tiarella cordifolia L., Saxifragaceae (Tiarella); nomenclature for all species follows Gleason \& Cronquist (1991). Figure 1 illustrates leaf phenology of the three study species in relation to canopy development and photosynthetic photon flux density (PPFD) at the forest floor.

The case of Tiarella is complicated because the closely related species Mitella diphylla also occurs in this stand. Because the two species are very difficult to distinguish when not flowering (Voss 1985), it is likely that some non-flowering individuals of $M$. diphylla were mistaken for Tiarella in this study. However, in addition to being closely related phylogenetically, these two species appear indistinguishable in terms of phenology, life history, and several parameters of leaf physiology and biochemistry (Rothstein 1999). 
724

D. E. Rothstein \&

D. R. Zak

(C) 2001 British

Ecological Society, Functional Ecology, 15, 722-731
The abiotic environment below the forest canopy was characterized by monitoring PPFD and air temperature at the forest floor. Four platforms, each supporting one Li-Cor quantum sensor (Li-Cor Inc., Lincoln, NE), were located $\approx 15 \mathrm{~cm}$ above-ground at $5 \mathrm{~m}$ intervals along a $20 \mathrm{~m}$ east-west transect in the centre of the stand. These sensors measured PPFD every $60 \mathrm{~s}$ and wrote hourly averages to two LI-1000 Data Loggers (Li-Cor). Daily averages of the hourly averages (daylight hours only) were used to document seasonal changes in light intensity at the forest floor (Fig. 1).

Physiological measurements were made once each in the spring, summer and autumn 1997 on all species with green leaves present; sampling dates for each species are shown in Fig. 1. For each species/season combination, 10 plants were selected by walking a transect (random start point) through the stand and collecting the nearest plant to each $20 \mathrm{~m}$ increment along that transect. In the case of Allium, ramets that were connected to others were rejected and the nearest solitary ramet was selected. Because both Tiarella and Allium reproduce clonally, we could not be certain that each ramet was a genetically distinct individual. However, by sampling at $20 \mathrm{~m}$ intervals we avoided selecting ramets from single patches. Five of the 10 plants were used for gas-exchange measurements, and the remaining five plants were used for analysis of leaf structure and chemistry.

\section{GAS-EXCHANGE MEASUREMENTS}

All photosynthetic measurements were carried out in the laboratory under controlled conditions. We were primarily interested in describing differences in inherent physiological characteristics, both within and among species, associated with seasonal changes in irradiance. Bringing plants into the laboratory allowed us to better control potentially confounding seasonal or diurnal variation in temperature and moisture. The plants were collected by digging up an intact cylinder of soil approximately $30 \mathrm{~cm}$ deep and $25 \mathrm{~cm}$ in diameter around the plant. These were placed in large $(\approx 101)$ buckets for transport to the field laboratory, which was located approximately $5 \mathrm{~min}$ from the field site. All buckets were watered to saturation and then allowed to drain to field capacity. Photosynthetic measurements were made on a single leaf of each plant using a LI6400 Portable Photosynthesis System (Li-Cor). For Allium and Tiarella, which have only basal leaves, the largest leaf was used for photosynthetic measurements. In the case of Viola, which has both basal and cauline leaves arising from a single rhizome, we always used the largest, lowermost cauline leaf.

Light-response curves of photosynthesis were generated for each plant with leaf temperature held constant at $20{ }^{\circ} \mathrm{C}$. Photosynthetically active radiation was varied from 2000 to $0 \mu \mathrm{mol} \mathrm{m}{ }^{-2} \mathrm{~s}^{-1}$ using a built-in red LED light source $(670 \mathrm{~nm})$. Ambient $\mathrm{CO}_{2}$ concentration was held constant at $350 \mu \mathrm{mol} \mathrm{mol}^{-1}$ by scrubbing incoming air with soda lime and then mixing in the appropriate amount of pure $\mathrm{CO}_{2}$. Before initiating the light-response curve, each plant was maintained at maximum irradiance until net assimilation was constant; this took between 5 and $30 \mathrm{~min}$. The data for each plant were fitted to the model of Prioul \& Chartier (1977) using the PC software package PHOTOSYN ASSISTANT (Dundee Scientific, Dundee, Scotland). Light-saturated photosynthetic rate was estimated for each plant as the asymptote of this function, and the LCP of each plant was estimated as the PPFD at which net assimilation was 0 ( $x$-axis intercept).

We also measured the response of photosynthesis to changes in internal $\mathrm{CO}_{2}$ concentration $\left(C_{\mathrm{i}}\right)$ by decreasing the ambient $\mathrm{CO}_{2}$ in the air passing over the leaf in nine intervals ranging from 1000 to $0 \mu \mathrm{mol} \mathrm{mol}^{-1}$. Data from each plant were fitted to the model of Farquhar et al. (1980) using PHOTOSYN ASSISTANT, to estimate maximum carboxylation capacity $\left(V_{\text {cmax }}\right)$ and maximum rate of electron transport $\left(J_{\max }\right)$.

After completion of the photosynthetic measurements, we measured rates of leaf dark respiration $\left(R_{\mathrm{d}}\right)$ at $20^{\circ} \mathrm{C}$. Plants were kept in the dark for at least $1 \mathrm{~h}$ before measurement, then the $\mathrm{CO}_{2}$ flux from leaves was measured using the LI 6400 with the LED light source turned off. Ten measurements were made evenly over a $5 \mathrm{~min}$ period and then averaged to calculate a final value for each plant. Finally, leaf area ratio (LAR), or the ratio of leaf area $\left(\mathrm{cm}^{2}\right)$ to total plant dry weight $(\mathrm{g})$, was calculated for each plant.

\section{LEAF STRUCTURE AND BIOCHEMISTRY}

Concurrently with gas-exchange analyses, five additional plants of each species were collected and 12 $1 \cdot 3 \mathrm{~cm}^{2}$ leaf disks were punched from their leaves. Four of the 12 disks were randomly selected for each of the following measurements: chlorophyll content, ribulose bisphosphate carboxylase (Rubisco) content, leaf dry mass per area (LMA) and leaf nitrogen concentration. Leaf disks for chlorophyll determination were extracted in $5 \mathrm{ml} \mathrm{N}, N$-dimethylformamide, and absorbance of the extract was measured at 647 and $664.5 \mathrm{~nm}$. We determined total chlorophyll content using the equations of Inskeep \& Bloom (1985). Leaf disks for LMA determination were oven-dried and weighed; these disks plus the remaining leaf tissue also were analysed for total N using an NC 2500 Elemental Analyzer (CE Elantech Inc., Lakewood, NJ). Leaf disks for Rubisco determination were immediately frozen in liquid $\mathrm{N}_{2}$ for transport to laboratory facilities at the University of Michigan, Ann Arbor, MI, where they were stored at $-70{ }^{\circ} \mathrm{C}$ prior to analysis.

Rubisco content was determined by sodium dodecyl sulfate polyacrylamide gel electrophoresis (SDS-PAGE; Hanes \& Rickwood 1990). The leaf disks were ground on ice with $1 \mathrm{ml}$ extraction buffer (50 mM HEPES, $2 \mathrm{~mm}$ EDTA, 1\% [w/v] polyvynilpyrrolidone $\mathrm{pH} 7 \cdot 5$ ), then centrifuged at $10000 \mathrm{~g}$ at $5^{\circ} \mathrm{C}$ for $10 \mathrm{~min}$. A $500 \mu \mathrm{l}$ aliquot of the supernatant was mixed with an 
Photosynthetic characteristics of deciduous-forest herbs
(C) 2001 British Ecological Society, Functional Ecology, 15, 722-731 equal volume of SDS buffer [62.5 mm Tris, $2 \%(\mathrm{w} / \mathrm{v})$ SDS, 5\% (v/v) glycerol, 5\% (v/v) mercaptoethanol, $0 \cdot 01 \%(\mathrm{w} / \mathrm{v})$ bromophenol blue $\mathrm{pH} 6 \cdot 8$ ] and boiled for 2-3 min. Samples of $15 \mu 1$ were loaded onto $12 \%$ acrylamide gels and electrophoresed for $4-5 \mathrm{~h}$ at $30 \mathrm{~mA}$.

In addition to leaf extracts, each gel also contained samples of a $24-380 \mu \mathrm{g} \mathrm{ml}^{-1}$ serial dilution of purified spinach Rubisco (courtesy of Dr R. L. Houtz, University of Kentucky) in extraction buffer. Separated proteins were stained with Coomassie Blue R-250. The large subunit of Rubisco was identified as the predominant band at $55 \mathrm{kDa}$ (Andrews \& Lorimer 1987), and the absorbance of this band was determined by laser densitometry (Ultrascan XL; LKB, Bromma, Sweden). Absorbances of the $55 \mathrm{kDa}$ band of the purified samples were used to generate a standard curve from which to estimate the Rubisco content of the unknown samples. This method may overestimate the amount of Rubisco in leaves by including other soluble proteins that resolve at $55 \mathrm{kDa}$. However, because Rubisco is by far the dominant leaf protein, making up to $50 \%$ of total soluble leaf protein (Andrews \& Lorimer 1987), any overestimation is likely to be slight.

\section{LEAF TRACKING IN VIOLA}

Because the decrease in photosynthetic capacity and LMA from spring to summer was so pronounced in Viola (see Results), we felt it necessary to confirm that these changes were truly occurring in individual leaves. Given that Viola had the most complex shoot architecture, we wanted to confirm that this species did not have separate spring and summer cohorts of leaves. To resolve this question we identified 10 Viola ramets in the field, and labelled the petiole of one leaf on each plant with a small plastic tag. From late April to late July (1998), we measured $A_{\max }$ in situ on each leaf at $1500 \mu \mathrm{mol} \mathrm{m}{ }^{-2} \mathrm{~s}^{-1}$ PPFD, $20^{\circ} \mathrm{C}$, and $350 \mu \mathrm{mol} \mathrm{mol}^{-1}$ $\mathrm{CO}_{2}$. In addition, we conducted regular measurements of the area of each leaf by measuring its width and length. These width and length measurements were used in a previously determined regression equation to calculate Viola leaf area $(\mathrm{LA}=1 \cdot 389$ (length) $+5 \cdot 485$ (width) $-17 \cdot 479 ; R^{2}=0 \cdot 975 ; n=20$ ).

\section{WHOLE-PLANT GROWTH}

Approximately 75 ramets of each species were collected for analysis of whole-plant growth when their new leaves began to emerge in the spring of 1997 (April 6-10 for Allium, April 22-26 for Viola, and May 10-13 for Tiarella). Each plant was collected using a shovel, with most of its root system intact, assigned an identifying number, washed free of soil particles with tap water, blotted dry, and weighed. A randomly selected subsample of 15 plants from each species (hereafter referred to as 'initial' plants) was dried to a constant weight in a $70^{\circ} \mathrm{C}$ oven and then reweighed. All other plants were placed in $10 \mathrm{~cm}$ diameter by $15 \mathrm{~cm}$ deep
PVC cores sealed at the bottom with a fine nylon mesh ( $\approx 1 \mathrm{~mm}$ openings). Each core was filled with homogenized native soil and placed back in the ground in the original stand. Randomly selected harvests of 10 plants of each species were made throughout the next year to coincide with important phenological events (e.g. top senescence for Allium, canopy leaf senescence for Tiarella). At each harvest the plants were washed free of soil particles with tap water, oven-dried $\left(70{ }^{\circ} \mathrm{C}\right)$ to a constant weight, and weighed.

The initial harvest of 15 plants for each species was used to determine the relationships between initial fresh weight (FW) and initial dry weight (DW). These were:

$$
\text { Allium, DW }=0 \cdot 1891(\mathrm{FW})-0 \cdot 1641, r^{2}=0.968
$$
eqn 1

Viola $, \mathrm{DW}=0 \cdot 1878(\mathrm{FW})+0 \cdot 0032, r^{2}=0.922$ eqn 2

Tiarella, DW $=0 \cdot 2068(\mathrm{FW})-0 \cdot 118, r^{2}=0 \cdot 846$. eqn 3

These equations were used to estimate the initial dry weights of each of the remaining plants. Relative dry matter accumulation $\left(\mathrm{g} \mathrm{g}^{-1}\right)$ for each harvested plant was calculated by subtracting the estimate of its initial dry weight from its final dry weight and dividing by the estimate of initial dry weight. Because Tiarella experienced significant mortality in June and July $(\approx 33 \%)$, the three subsequent harvests each comprised five plants. There was very little mortality of Viola $(\approx 3 \%)$ or Allium $(\approx 10 \%)$ during the experiment. There were no other apparent effects of transplanting, and none of the containers was root-bound at harvest.

\section{STATISTICAL ANALYSES}

For gas-exchange data, the parameters $A_{\max }$, LCP, $V_{\text {cmax }}, J_{\text {max }}$ and $R_{\mathrm{d}}$ were estimated for each plant. These values were then used to generate means and variances for each species/season combination $(n=5)$. Because leaves of all three species were not present in all three seasons, gas-exchange and leaf parameters were analysed using a one-way ANOVA with species/season as a single factor (six levels). Differences in means between all six species/season combinations were evaluated using Tukey's HSD test.

Because each species was sampled at a unique set of times throughout the year in the whole-plant growth experiment, we took the same approach of treating species/sampling date as a single factor for ANOVA. However, in this case we were faced with 15 means (three species $\times$ five dates) to compare. In order to protect for the overall experimental $\alpha$, without sacrificing statistical power, we selected five a priori, ecologically important pairwise comparisons. We made these contrasts using the Bonferroni procedure with probabilities adjusted for five pairwise comparisons. 
(a)

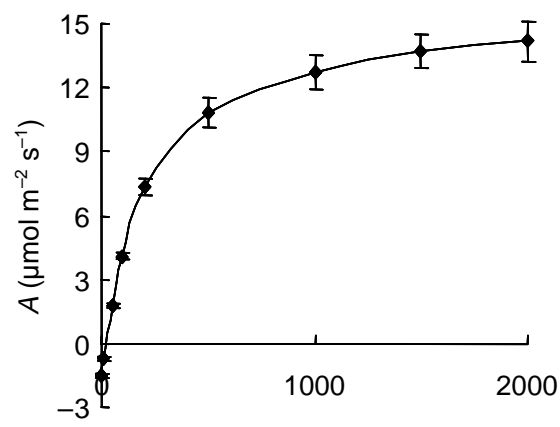

Viola

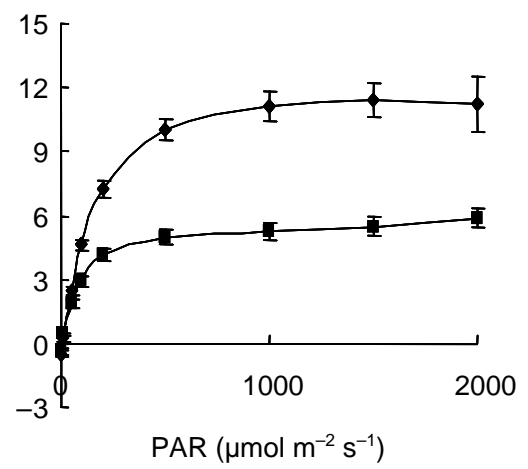

Tiarella

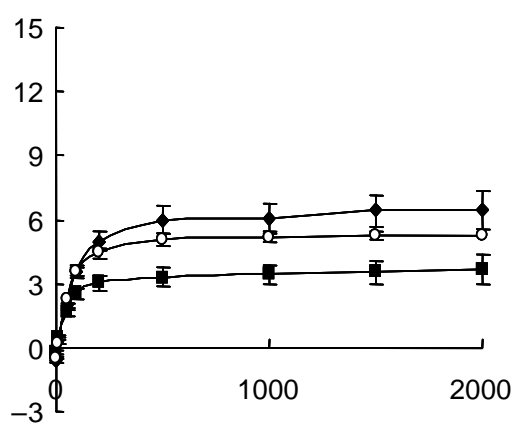

(b)
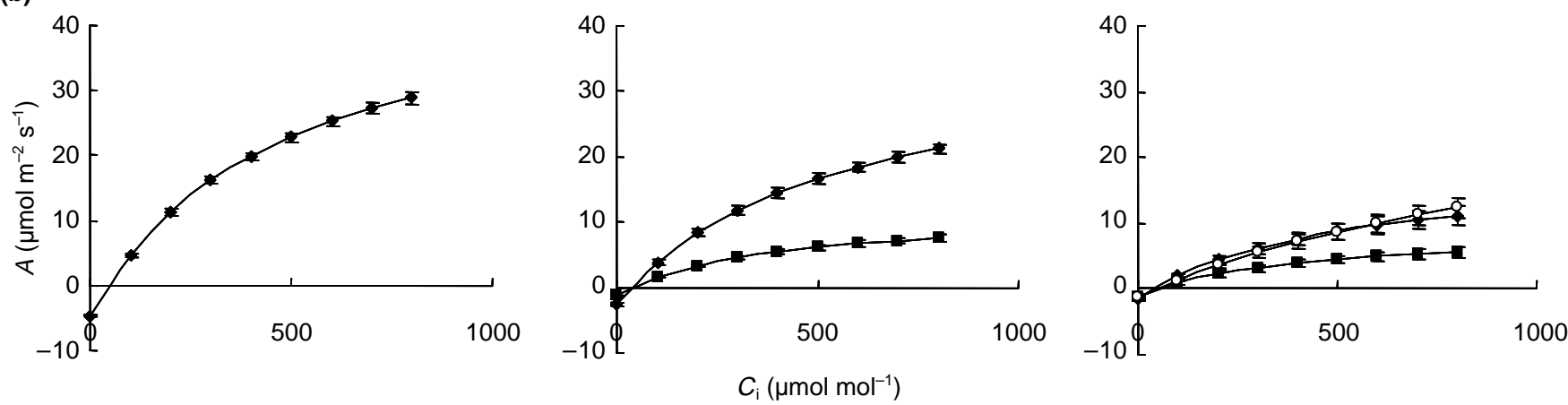

Fig. 2. (a) Light- and (b) $C_{\mathrm{i}}$-response curves of photosynthesis in Allium tricoccum, Viola pubescens and Tiarella cordifolia throughout the year. Values in each panel represent (a) mean assimilation rates for a given PPFD $\pm 1 \mathrm{SE}$; (b) mean $( \pm 1 \mathrm{SE})$ assimilation rates for intervals of $C_{\mathrm{i}}$, estimated from fitted data for individual plants. Response curves in the different seasons are represented by the following symbols: spring $(\bullet)$, summer $(\mathbf{\square})$ and autumn $(\bigcirc)$.

Table 1. Area-based values for parameters associated with leaf gas exchange of Allium, Viola and Tiarella over time

\begin{tabular}{|c|c|c|c|c|c|c|}
\hline \multirow[b]{2}{*}{ Parameter } & \multicolumn{3}{|l|}{ Spring } & \multicolumn{2}{|l|}{ Summer } & \multirow{2}{*}{$\begin{array}{l}\text { Autumn } \\
\text { Tiarella }\end{array}$} \\
\hline & Allium & Viola & Tiarella & Viola & Tiarella & \\
\hline$A_{\max }$ & $15 \cdot 4 \pm 0.94 \mathrm{a}$ & $12 \cdot 1 \pm 0 \cdot 66 \mathrm{~b}$ & $6 \cdot 8 \pm 0.65 \mathrm{c}$ & $5 \cdot 6 \pm 0 \cdot 45 \mathrm{~cd}$ & $3.9 \pm 0.54 \mathrm{~d}$ & $5 \cdot 4 \pm 0.34 \mathrm{~cd}$ \\
\hline LCP & $21.6 \pm 1.42 \mathrm{a}$ & $8 \cdot 4 \pm 1 \cdot 3 b$ & $9 \cdot 0 \pm 0.95 b$ & $4 \cdot 1 \pm 0.94 b c$ & $3.2 \pm 0.53 c$ & $6.5 \pm 0.75 b c$ \\
\hline$V_{\text {cmax }}$ & $40 \cdot 0 \pm 1 \cdot 37 \mathrm{a}$ & $29 \cdot 1 \pm 1 \cdot 25 \mathrm{~b}$ & $15 \cdot 2 \pm 1 \cdot 86 \mathrm{c}$ & $12 \cdot 7 \pm 1.08 \mathrm{~cd}$ & $8 \cdot 1 \pm 1 \cdot 37 \mathrm{~d}$ & $16.9 \pm 0.78 \mathrm{c}$ \\
\hline$J_{\max }$ & $146 \cdot 0 \pm 7 \cdot 59 \mathrm{a}$ & $107 \cdot 6 \pm 4 \cdot 86 \mathrm{~b}$ & $51 \cdot 6 \pm 6 \cdot 07 \mathrm{~cd}$ & $43 \cdot 6 \pm 7 \cdot 03 \mathrm{~cd}$ & $31 \cdot 1 \pm 5 \cdot 46 \mathrm{~d}$ & $59 \cdot 3 \pm 4 \cdot 24 \mathrm{c}$ \\
\hline$R_{\mathrm{d}}$ & $1.29 \pm 0.037 \mathrm{a}$ & $0 \cdot 80 \pm 0.033 \mathrm{~b}$ & $0 \cdot 34 \pm 0 \cdot 017 \mathrm{c}$ & $0 \cdot 20 \pm 0.003 \mathrm{~d}$ & $0 \cdot 20 \pm 0 \cdot 005 \mathrm{~d}$ & $0.53 \pm 0.023 \mathrm{e}$ \\
\hline
\end{tabular}

Leaf $\mathrm{CO}_{2}$ exchange is described by $A_{\max }\left(\mu \mathrm{mol} \mathrm{CO} \mathrm{C}^{-2} \mathrm{~s}^{-1}\right) ; \mathrm{LCP}\left(\mu \mathrm{mol} \mathrm{m} \mathrm{s}^{-1} \mathrm{PAR}\right) ; V_{\text {cmax }}\left(\mu \mathrm{mol} \mathrm{m} \mathrm{s}^{-1}\right) ; J_{\max }\left(\mu \mathrm{mol} \mathrm{m} \mathrm{m}^{-2}\right)$; and leaf dark respiration $\left(\mu \mathrm{mol} \mathrm{CO} \mathrm{CO}_{2} \mathrm{~m}^{-2} \mathrm{~s}^{-1}\right)$. Means within a row followed by the same letter are not significantly different according to Tukey's HSD test $(P>0 \cdot 05)$.

All statistical analyses were performed using SYSTAT for personal computers (Wilkinson 1990), and significance was accepted at $\alpha=0 \cdot 05$.

\section{Results}

Allium exhibited typical sun-plant characteristics; Viola exhibited acclimation from sun-plant characteristics in the spring to shade-plant characteristics in the summer; and Tiarella exhibited shade-plant characteristics with a relatively narrow range of acclimation

(C) 2001 British Ecological Society, Functional Ecology, $15,722-731$ throughout the growing season. A broad picture of this response is illustrated in Fig. 2, which presents the light- and $C_{\mathrm{i}}$-response curves of photosynthesis for all three species. The large changes in photosynthetic response of Viola are in clear contrast to the narrowly changing response of Tiarella. Species-season combination had significant effects $(P<0.001)$ on all five area-based parameters associated with $\mathrm{CO}_{2}$ exchange (Table 1). Rates of $A_{\max }$, LCP, $V_{\text {cmax }}, J_{\max }$ and leaf dark respiration in Allium all significantly exceeded those of the other species, irrespective of season. In the spring, gas-exchange parameters in Viola were comparable to those of Allium, but declined from spring to summer. Tiarella exhibited smaller decreases in gas-exchange parameters from spring to summer. In addition, Tiarella exhibited trends of increasing photosynthetic capacity from summer to autumn, although the increases in $A_{\max }(P=0.529)$ and LCP $(P=0.248)$ were not statistically significant. 
Photosynthetic characteristics of deciduous-forest herbs
(C) 2001 British Ecological Society, Functional Ecology, 15, 722-731
Species/season combination had significant effects on all area-based parameters associated with leaf morphology and chemistry $(P<0 \cdot 001$; Table 2$)$. Differences in leaf morphology are indicated by differences in LMA which varied between species, and between seasons in Viola. Allium had significantly greater LMA than Tiarella in all seasons, and than Viola in the summer. The LMA of Viola leaves decreased from spring to summer, whereas Tiarella leaves did not change seasonally. There were no significant differences in LAR (the ratio of total leaf area to total plant biomass) between species, but LAR increased from spring to summer in Viola and Tiarella.

In general, leaf $\mathrm{N}$ and Rubisco responded similarly across all species/season combinations. They decreased across species in the spring from Allium to Viola to Tiarella, and decreased within Viola from spring to summer. There was no change in leaf $\mathrm{N}$ content across seasons for Tiarella; however, leaf Rubisco content in this species decreased from spring to summer, and increased from summer to autumn $(P=0.063)$. The general pattern for leaf chlorophyll content was opposite to that of $\mathrm{N}$ and Rubisco, being higher in Viola and Tiarella than in Allium in the spring. Chlorophyll content increased significantly in Viola and Tiarella from spring to summer, and decreased in Tiarella from summer to autumn. The chlorophyll : $\mathrm{N}$ ratio increased significantly from spring to summer in Viola and Tiarella, and decreased significantly from summer to autumn in Tiarella. The Rubisco : $\mathrm{N}$ ratio decreased from spring to summer in Tiarella, but increased slightly in Viola $(P=0 \cdot 199)$.

Because of the large changes in LMA in Viola, comparisons of leaf and gas-exchange parameters solely on an area basis can be misleading. For this reason, gas-exchange and biochemical parameters are presented on a mass basis in Table 3. Expressing these parameters on a mass basis factors out the effects of changes in LMA and reflects only changes in tissue biochemistry. Leaf gas exchange and chemistry expressed on a mass basis did not change any of the patterns between and within species, and makes it clear that photosynthetic acclimation in Viola is due to structural and biochemical changes in its leaves.

Patterns of leaf area and $A_{\max }$ tracked on individual Viola leaves throughout the spring and summer of

Table 2. Area-based values for parameters associated with leaf chemistry and morphology

\begin{tabular}{|c|c|c|c|c|c|c|}
\hline \multirow[b]{2}{*}{ Parameter } & \multicolumn{3}{|l|}{ Spring } & \multicolumn{2}{|l|}{ Summer } & \multirow{2}{*}{$\begin{array}{l}\text { Autumn } \\
\text { Tiarella }\end{array}$} \\
\hline & Allium & Viola & Tiarella & Viola & Tiarella & \\
\hline \multicolumn{7}{|l|}{ Leaf chemistry } \\
\hline $\mathrm{N}$ & $1 \cdot 83 \pm 0 \cdot 104 \mathrm{a}$ & $1 \cdot 51 \pm 0 \cdot 113 \mathrm{a}$ & $0 \cdot 83 \pm 0.062 b$ & $0 \cdot 61 \pm 0.031 \mathrm{~b}$ & $0.69 \pm 0.070 \mathrm{~b}$ & $0 \cdot 76 \pm 0.043 b$ \\
\hline Chlorophyll & $0 \cdot 20 \pm 0 \cdot 008 \mathrm{a}$ & $0 \cdot 30 \pm 0 \cdot 002 \mathrm{~b}$ & $0 \cdot 28 \pm 0 \cdot 013 \mathrm{~b}$ & $0 \cdot 42 \pm 0 \cdot 011 \mathrm{c}$ & $0 \cdot 44 \pm 0.026 \mathrm{c}$ & $0 \cdot 32 \pm 0 \cdot 011 \mathrm{~b}$ \\
\hline Rubisco & $2 \cdot 83 \pm 0.209 \mathrm{a}$ & $1.84 \pm 0.246 \mathrm{~b}$ & $1 \cdot 47 \pm 0 \cdot 116 b c$ & $0.93 \pm 0.073 \mathrm{~cd}$ & $0 \cdot 50 \pm 0 \cdot 165 \mathrm{~d}$ & $0 \cdot 78 \pm 0 \cdot 108 \mathrm{~cd}$ \\
\hline Chlorophyll : N & $0 \cdot 11 \pm 0.009 \mathrm{a}$ & $0 \cdot 20 \pm 0 \cdot 015 \mathrm{ab}$ & $0.34 \pm 0.028 \mathrm{bd}$ & $0.69 \pm 0.041 \mathrm{c}$ & $0 \cdot 66 \pm 0.080 \mathrm{c}$ & $0 \cdot 43 \pm 0 \cdot 016 \mathrm{~d}$ \\
\hline Rubisco : N & $1.56 \pm 0.086 \mathrm{ab}$ & $1.20 \pm 0.089 \mathrm{ab}$ & $1 \cdot 84 \pm 0.238 \mathrm{a}$ & $1.51 \pm 0.058 \mathrm{ab}$ & $0.82 \pm 0.330 \mathrm{~b}$ & $1 \cdot 06 \pm 0 \cdot 181 \mathrm{ab}$ \\
\hline \multicolumn{7}{|l|}{ Morphology } \\
\hline LMA & $37 \cdot 1 \pm 3 \cdot 20 a$ & $30 \cdot 2 \pm 1 \cdot 88 \mathrm{ab}$ & $26.9 \pm 1.25 b c$ & $19 \cdot 8 \pm 0 \cdot 22 \mathrm{c}$ & $26 \cdot 0 \pm 1 \cdot 38 b c$ & $30 \cdot 3 \pm 1 \cdot 11 b c$ \\
\hline LAR & $97 \cdot 9 \pm 2 \cdot 10 \mathrm{a}$ & $98.0 \pm 4.63 \mathrm{a}$ & $112 \pm 4.63 \mathrm{ab}$ & $155 \pm 9 \cdot 77 \mathrm{bc}$ & $166 \pm 17 \cdot 75 \mathrm{c}$ & $129 \pm 6 \cdot 74 \mathrm{abc}$ \\
\hline
\end{tabular}

The chemistry of leaves is described by their content of $\mathrm{N}$, chlorophyll and Rubisco (all in $\mathrm{g} \mathrm{m}^{-2}$ ), and ratios of chlorophyll to $\mathrm{N}$, Rubisco to N, and Rubisco to chlorophyll (all in $\mathrm{g} \mathrm{g}^{-1}$ ). Morphology is described by leaf mass per area (LMA; $\mathrm{g} \mathrm{m}^{-2}$ ) and leaf area ratio $\left(\mathrm{LAR} ; \mathrm{cm}^{2} \mathrm{~g}^{-1}\right)$. Means within a row followed by the same letter are not significantly different according to Tukey's HSD test $(P>0 \cdot 05)$.

Table 3. Mass-based values for selected parameters associated with leaf gas exchange and leaf chemistry of Allium, Viola and Tiarella over time

\begin{tabular}{|c|c|c|c|c|c|c|}
\hline \multirow[b]{2}{*}{ Parameter } & \multicolumn{3}{|l|}{ Spring } & \multicolumn{2}{|l|}{ Summer } & \multirow{2}{*}{$\begin{array}{l}\text { Autumn } \\
\text { Tiarella }\end{array}$} \\
\hline & Allium & Viola & Tiarella & Viola & Tiarella & \\
\hline \multicolumn{7}{|c|}{$\mathrm{CO}_{2}$ exchange } \\
\hline $\begin{array}{l}A_{\max } \\
R_{\mathrm{d}}\end{array}$ & $\begin{array}{r}432 \pm 55 \cdot 0 a \\
35 \cdot 8 \pm 3 \cdot 16 a\end{array}$ & $\begin{array}{l}409 \pm 35 \cdot 6 \mathrm{ab} \\
26 \cdot 9 \pm 1 \cdot 22 \mathrm{~b}\end{array}$ & $\begin{array}{c}254 \pm 28 \cdot 1 \mathrm{c} \\
12 \cdot 5 \pm 0 \cdot 72 \mathrm{~cd}\end{array}$ & $\begin{array}{c}281 \pm 21 \cdot 1 \mathrm{~b} \\
10 \cdot 2 \pm 0 \cdot 23 \mathrm{c}\end{array}$ & $\begin{array}{r}154 \pm 29 \cdot 5 \mathrm{c} \\
7 \cdot 9 \pm 0 \cdot 61 \mathrm{c}\end{array}$ & $\begin{array}{c}178 \pm 8 \cdot 6 \mathrm{c} \\
17 \cdot 6 \pm 0.96 \mathrm{~d}\end{array}$ \\
\hline \multicolumn{7}{|l|}{ Chemistry } \\
\hline $\mathrm{N}$ & $49 \cdot 8 \pm 2 \cdot 24 \mathrm{a}$ & $49 \cdot 9 \pm 1 \cdot 32 \mathrm{a}$ & $31 \cdot 2 \pm 3 \cdot 26 \mathrm{~b}$ & $30 \cdot 6 \pm 1 \cdot 31 \mathrm{~b}$ & $26 \cdot 5 \pm 1 \cdot 73 \mathrm{~b}$ & $25 \cdot 0 \pm 1 \cdot 07 \mathrm{~b}$ \\
\hline Chlorophyll & $5.45 \pm 0.622 \mathrm{a}$ & $10 \cdot 1 \pm 0 \cdot 574 \mathrm{~b}$ & $10 \cdot 5 \pm 0 \cdot 817 \mathrm{~b}$ & $21 \cdot 0 \pm 0.578 \mathrm{c}$ & $17 \cdot 1 \pm 1.769 \mathrm{c}$ & $10 \cdot 6 \pm 0 \cdot 206 b$ \\
\hline Rubisco & $77 \cdot 0 \pm 3 \cdot 67 \mathrm{a}$ & $60 \cdot 2 \pm 5 \cdot 61 \mathrm{ab}$ & $55 \cdot 4 \pm 5.07 \mathrm{ac}$ & $46 \cdot 6 \pm 3 \cdot 37 \mathrm{bc}$ & $20 \cdot 4 \pm 7 \cdot 77 \mathrm{~d}$ & $26 \cdot 2 \pm 4 \cdot 154 \mathrm{~cd}$ \\
\hline
\end{tabular}

Leaf gas exchange is described by $A_{\max }$ and $R_{\mathrm{d}}$ (both in $\mu \mathrm{mol} \mathrm{CO} \mathrm{Cg}^{-2} \mathrm{~s}^{-1}$ ), and the chemistry of leaves by their content of $\mathrm{N}$, chlorophyll and Rubisco (all in $\mathrm{g} \mathrm{kg}^{-1}$ ). Means within a row followed by the same letter are not significantly different according to Tukey's HSD test $(P>0 \cdot 05)$. 


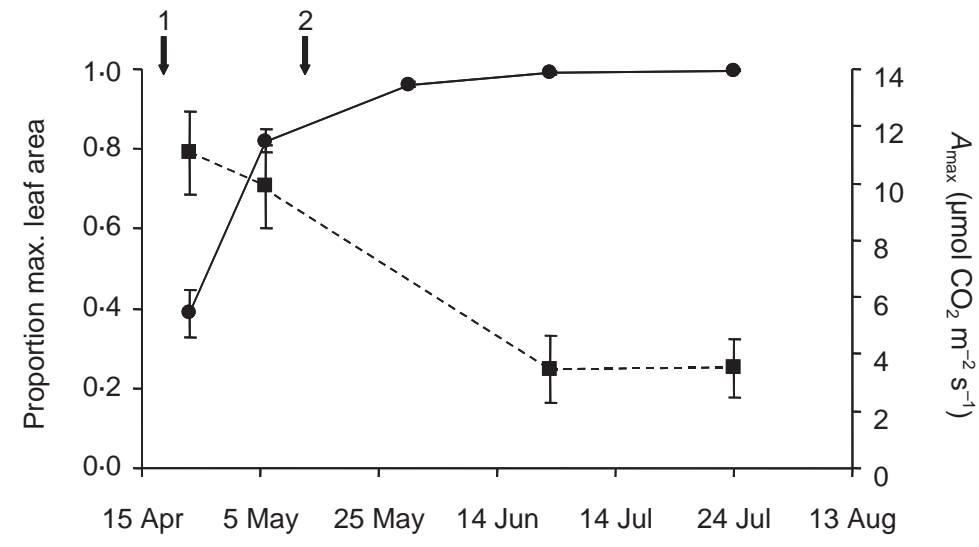

Fig. 3. Patterns of $A_{\max }(\mathbf{\square})$ and proportion of maximum leaf area (0) of individual Viola pubescens leaves through the spring and summer of 1998. Values represent the means ( $\pm 1 \mathrm{SE})$ of 10 individual leaves which were labelled at the first sampling date and resampled at each subsequent date. Leaf area is expressed as the proportion of the maximal value attained for each leaf at each sampling date. The numbered arrows at the top of the figure represent the timing of (1) canopy bud-break; (2) completion of canopy leaf expansion.

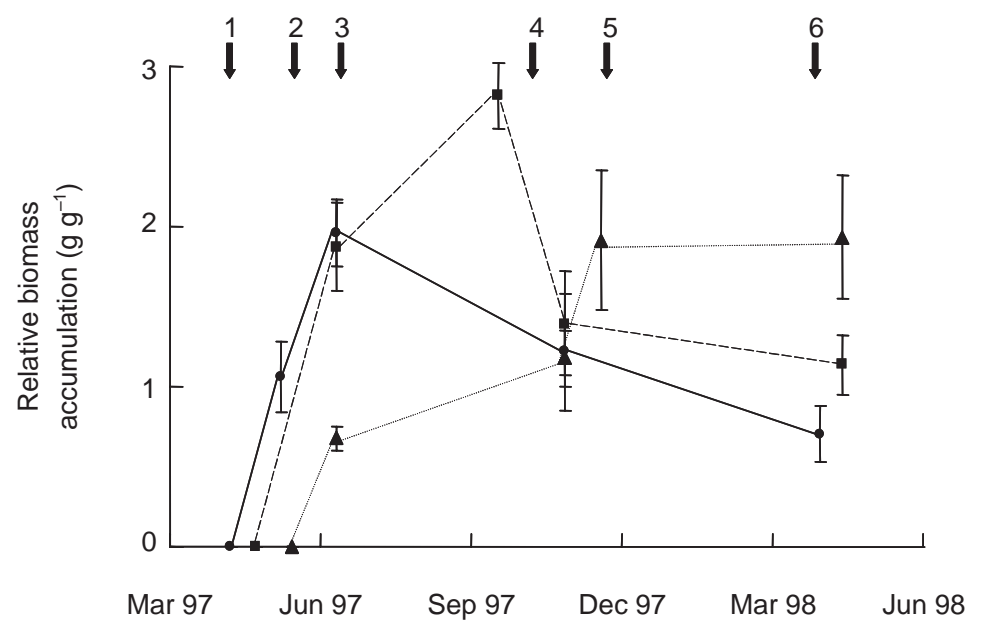

Fig. 4. Relative biomass accumulation of Allium tricoccum $(\mathbf{\bullet})$, Viola pubescens $(\mathbf{\square})$, and Tiarella cordifolia $(\boldsymbol{\Delta})$ throughout one full year. Values represent means $( \pm 1 \mathrm{SE})$ of 10 plants, except for the final three samples of $T$. cordifolia, which were of five plants each. The numbered arrows at the top represent the timing of the following events: (1) 1997 snow-melt; (2) beginning of canopy bud-break; (3) canopy at full leaf expansion; (4) beginning of canopy leaf senescence; (5) first snow accumulation; and (6) 1998 snow-melt.

(C) 2001 British Ecological Society, Functional Ecology, $15,722-731$
1998 confirm that decreases in $A_{\max }$ and LMA occurred on individual leaves and were not simply the result of measurements on different cohorts of leaves (Fig. 3). In addition, values of $A_{\max }$ taken from undisturbed plants in the field $\left(11.0 \mu \mathrm{mol} \mathrm{m} \mathrm{m}^{-2} \mathrm{~s}^{-1}\right)$ are consistent with those for plants collected and transplanted to buckets $\left(12 \cdot 1 \mu \mathrm{mol} \mathrm{m}{ }^{-2} \mathrm{~s}^{-1}\right)$.

Patterns of whole-plant relative growth highlighted the importance of the spring light phase for all three species, and the autumn light phase for Tiarella alone (Fig. 4). All three species accumulated biomass rapidly during the spring light phase; however, Allium lost biomass from that point, whereas Viola and Tiarella continued to accrue biomass. Viola had a sharp reduction in biomass in the late summer, coincident with above-ground dieback, and then slowly lost biomass over the winter. Approximately $75 \%$ of the biomass gain by Tiarella came during the spring and autumn light phases. In Viola, approximately $66 \%$ of its biomass gain came during the spring light phase, whereas Allium's entire annual biomass gain came during this period.

Pairwise comparisons of final (after 1 year) relative growth were made between all three species. In addition, pairwise comparisons of relative growth in Tiarella were made between the October 261997 sampling date and the two subsequent sampling dates. After one full year of growth, net relative growth was significantly greater in Tiarella compared to Allium $(P=0.032)$. $V i o l a$ 's final relative growth was intermediate between, and not significantly different from, either Allium $(P=0 \cdot 139)$ or Tiarella $(P=0 \cdot 625)$. Tiarella's relative growth at the October 261997 sampling date was not significantly different from relative growth at the November $171997(P=0 \cdot 441)$ or April 111998 $(P=0 \cdot 144)$ sample dates.

\section{Discussion \\ PHOTOSYNTHETIC ADAPTATION AND ACCLIMATION}

The three understorey herbs studied differed in their photosynthetic characteristics in ways that were consistent with differences in their above-ground phenologies. Not surprisingly, the spring ephemeral species Allium had the highest $A_{\max }$ and $R_{\mathrm{d}}$, followed by the summer-green Viola, and then the semi-evergreen Tiarella. These broad patterns between species of deciduous-forest herbs with differing phenologies have been demonstrated by previous researchers (reviewed by Hicks \& Chabot 1985). A more unusual pattern to emerge from the gas-exchange data was the photosynthetic acclimation of Viola and Tiarella leaves across the seasons. In Viola, acclimation from spring to summer resulted in a decline in area-based $A_{\max }$ from $12 \cdot 1$ to $5.6 \mu \mathrm{mol} \mathrm{m} \mathrm{m}^{-1}$ and a decline in area-based $R_{\mathrm{d}}$ from $0 \cdot 8$ to $0 \cdot 2 \mu \mathrm{mol} \mathrm{m}^{-2} \mathrm{~s}^{-1}$. This range of acclimation was much greater than that exhibited by Tiarella over the same period (declines in $A_{\max }$ from 6.8 to $3.9 \mu \mathrm{mol}$ $\mathrm{m}^{-2} \mathrm{~s}^{-1}$, and $R_{\mathrm{d}}$ from $0 \cdot 34$ to $0 \cdot 2 \mu \mathrm{mol} \mathrm{m} \mathrm{m}^{-2} \mathrm{~s}^{-1}$ ). The only report of photosynthetic acclimation of a summergreen species from the literature which compares to that reported here for Viola was a decrease in $A_{\max }$ from approximately $11-4 \mu \mathrm{mol} \mathrm{m} \mathrm{m}^{-2} \mathrm{~s}^{-1}$ in Solidago flexicaulis (Taylor \& Pearcy 1976). In contrast, Graves (1990) observed a decrease in $A_{\max }$ from 5 to $3 \mu \mathrm{mol} \mathrm{m} \mathrm{m}^{-2}$ (equivalent to the acclimation we observed in Tiarella) in leaves of Mercurialis perennis, whereas Landhausser et al. (1997) observed little or no change in assimilation rates in Rubus pubescens and Aralia nudicaulis.

Also remarkable was Tiarella's reversal of its initial acclimation, in which it increased the photosynthetic capacity of its leaves from summer to autumn. Although some of the summer to autumn increases in 
729

Photosynthetic

characteristics of

deciduous-forest

herbs leaf gas-exchange parameters were not statistically significant, the overwhelming number of leaf parameters that changed in the direction of a more sun-acclimated condition (Fig. 2; Tables 1 and 2) suggests that this is an ecologically significant pattern. Similar upregulation of photosynthetic capacity after canopy leaf drop in the autumn has been reported for Pachysandra terminalis (Yoshie \& Kawano 1986) and Hexastylis arifolia (Skillman et al. 1996). However, the potential for leaf acclimation from summer to autumn is by no means the rule for evergreen and semi-evergreen herbs of temperate deciduous forests (Landhausser et al. 1997; Oberhuber \& Bauer 1991; Pitelka \& Curtis 1986; Tissue et al. 1995).

\section{MECHANISMS OF ADAPTATION AND ACCLIMATION}

Photosynthetic acclimation appears to occur in Viola leaves through structural and biochemical changes, whereas leaf acclimation is solely biochemical in Tiarella. In Viola, it appears that decreasing LMA, presumably due to leaf expansion, accounts for approximately half of the decrease in $A_{\max }$ from spring to summer; compare the $31 \%$ decrease in mass-based $A_{\text {max }}$ (Table 3) to the $54 \%$ decrease in area-based $A_{\max }$ (Table 1). It could be argued that these differences are an artefact of leaf development, and that the spring values represent immature leaves. However, we took our first LMA and gas-exchange measurements on Viola approximately 4 weeks after its leaves first emerged, yet there was still a 34\% decline in LMA from spring to midsummer. In addition, repeated measurements of leaf area and photosynthesis on leaves of intact plants in 1998 (Fig. 3) demonstrate that these plants undergo continuous leaf expansion until well after the forest canopy closes. The 1998 data also preclude the possibility that the 1997 patterns in LMA and photosynthetic capacity were due to the measurement of two different cohorts of leaves.

Acclimation to changes in light environment can occur either through the production of new leaves or through chemical and/or structural changes to existing leaves (Pearcy \& Sims 1994). In species that can alter existing leaves in response to changes in irradiance, redistribution of leaf $\mathrm{N}$ is considered an important mechanism of acclimation. Optimality models of photosynthetic performance suggest that $\mathrm{N}$ within leaves should undergo redistribution from $\mathrm{CO}_{2}$ fixation and towards light harvesting as irradiance decreases (Evans 1989; Evans 1993; Friend 1991). For species whose mature leaves acclimate to shading, such redistributions of $\mathrm{N}$ have been inferred from increases in the chlorophyll : N ratio (Brooks et al. 1996) or from gasexchange data (Avalos \& Mulkey 1999). In this study, chlorophyll : $\mathrm{N}$ ratios increased from spring to summer in Viola and Tiarella, suggesting redistributions of leaf N (Table 2). However, analysis of Rubisco concentrations supports such a redistribution of leaf $\mathrm{N}$ only for Tiarella. Chlorophyll concentration increased in Viola from spring to summer with no decline in Rubisco concentration, and with a non-significant increase in Rubisco : $\mathrm{N}$ ratio (Table 2).

The most dramatic changes associated with sunshade acclimation in Viola were the decreases in leaf $\mathrm{N}$ (significant on both area and mass bases) and LMA. In contrast, neither parameter changed seasonally in Tiarella. Other researchers have shown thickening of mature leaves associated with shade to sun acclimation (Bauer \& Thöni 1988; Kamaluddin \& Grace 1992), but we are aware of no other studies which show significant decreases in LMA associated with sun to shade acclimation. Viola clearly shows a two-step ontogeny, including structural and chemical changes, allowing individual leaves to function as sun leaves in the spring and shade leaves during the summer. This combination of changes in leaf structure and total $\mathrm{N}$ content appears to explain the greater photosynthetic plasticity of Viola relative to Tiarella, in which acclimation results solely from redistribution of a consistent pool of leaf N. The limited range of photosynthetic acclimation in Tiarella also may be related to its leaf longevity. It is known that chemical and structural adaptations that enhance leaf persistence tend to limit photosynthetic capacity (Chabot \& Hicks 1982; Field \& Mooney 1986; Reich et al. 1992), and it is plausible that adaptations for leaf longevity also might limit photosynthetic plasticity.

\section{CONSEQUENCES OF PHOTOSYNTHETIC ACCLIMATION}

These patterns of photosynthetic acclimation in Viola and Tiarella suggest that their acclimation to increased photosynthetic capacity in the spring and autumn allows them to better exploit these brief periods of direct irradiance. Furthermore, acclimation resulting in reduced leaf dark respiration and a lower light compensation point during the summer allows them to maintain a positive carbon balance under deep shade. The daily average PPFD for July and August ranged from 3 to $13 \mu \mathrm{mol} \mathrm{m}{ }^{-2} \mathrm{~s}^{-1}$. In comparison, the LCPs of Viola and Tiarella decreased from 8.4 and $9 \mu \mathrm{mol} \mathrm{m} \mathrm{m}^{-1}$ in the spring to $4 \cdot 1$ and $3 \cdot 2 \mu \mathrm{mol} \mathrm{m} \mathrm{m}^{-1}$ in the summer. While the average daily PPFD was $\approx 10 \mu \mathrm{mol} \mathrm{m} \mathrm{s}^{-1}$ for much of the summer, nearly $70 \%$ of those days had at least one instantaneous PPFD above $100 \mu \mathrm{mol} \mathrm{m} \mathrm{m}^{-2} \mathrm{~s}^{-1}$. The continued accumulation of biomass by Viola and Tiarella after canopy closure probably reflects the efficient exploitation of such sunflecks (Chazdon 1988).

The disproportionate contribution of brief seasonal periods of direct irradiance to the growth of the shadetolerant species was borne out by our analysis of wholeplant biomass accumulation. Viola and Tiarella have dry matter accumulations equivalent to that of Allium in the spring, and then, presumably due to their photosynthetic acclimation, continue accruing biomass Functional Ecology, 15, 722-731 
730

D. E. Rothstein \&

D. R. Zak

after closure of the overstorey canopy. The importance of the spring light phase for Viola is demonstrated its accumulation of approximately $66 \%$ of its annual biomass increment in the 6 weeks of growth prior to canopy closure, and the remainder in the following 20 weeks.

Tiarella employs a similar strategy of accumulating biomass rapidly in the spring, and surviving the summer shade phase with little or no biomass growth ( $\approx 4$ months; Fig. 4). Despite its narrow range of photosynthetic acclimation, Tiarella achieved approximately $75 \%$ of its maximum relative growth in the spring and autumn light phases of approximately 1 month each. Although Tiarella's biomass accumulation in the autumn appears comparable to that during the spring, the increase in mean relative growth between the October 26 and November 17 sampling dates was not statistically significant $(P=0 \cdot 441)$. It is likely that this increase is real, particularly given the consistency between the November 1997 and April 1998 means, but that we were not able to detect it statistically. This is partly due to the high variability associated with these data, and partly to the halving of our sample size after the summer of 1997.

Despite having the lowest photosynthetic capacity of the three species, over the entire year Tiarella achieved a relative growth as great as, or greater than, that of the other two species. The fact that all three species had virtually identical biomass accumulation at the time of canopy leaf senescence in October 1997 highlights the importance of Tiarella's exploitation of direct irradiance in the autumn. While the other two species lost biomass from then on, Tiarella continued to accumulate biomass for at least another month.

\section{Conclusions}

Relatively brief, seasonal periods of high irradiance are essential for the growth of these three species of contrasting phenology. For the summer- and evergreen species, leaf-level acclimation appears to be the key to capitalizing on these brief windows of high irradiance, while still avoiding a negative carbon balance during the 4 months of deep shade during the summer. Viola, in particular, exhibited a remarkable range of photosynthetic acclimation, with the same leaves functioning as sun leaves in the spring and as shade leaves in the summer. This wide range of photosynthetic acclimation was the result of a combination of changes in total leaf $\mathrm{N}$ content and leaf structure. In contrast, Tiarella's narrow range of acclimation was associated with changes in leaf-level allocation alone.

\section{Acknowledgements}

(C) 2001 British

Ecological Society, Functional Ecology, 15, 722-731
We thank the USDA Forest Service, North Central Research Station for providing access to the field site and nearby laboratory space, and the USDA Forest Service, Manistee Ranger District for providing field housing. We also thank J. Guiamet, P. Elsner, R. Houtz and L. Nooden for their help with Rubisco determinations, M. Holley, M. Hyde and W. Holmes for their assistance in the field and laboratory, and B. Barnes, M. Kubiske, L. Nooden, K. Pregitzer and J. Teeri for providing helpful comments on earlier drafts of this manuscript. This project was supported through a graduate research fellowship from the Matthai Botanical Gardens, University of Michigan, and grants from Sigma Xi and the School of Natural Resources and Environment, University of Michigan.

\section{References}

Andrews, T.J. \& Lorimer, G.H. (1987) Rubisco: structure, mechanisms, and prospects for improvement. The Biochemistry of Plants: A Comprehensive Treatise (eds M.D. Hatch \& N.K. Boardman), pp. 131-218. Academic Press, San Diego, CA.

Avalos, G. \& Mulkey, S.S. (1999) Photosynthetic acclimation of the liana Stigmaphyllon lindenianum to light changes in a tropical dry forest canopy. Oecologia 120, 475-484.

Bauer, H. \& Thöni, W. (1988) Photosynthetic light acclimation in fully developed leaves of the juvenile and adult life phases of Hedera helix. Physiologia Plantarum 73, 3137.

Brooks, J.R., Sprugel D.G., \& Hinckley T.M., (1996) The effects of light acclimation during and after foliage expansion on photosynthesis of Abies amabilis foliage within the canopy. Oecologia 107, 21-32.

Chabot, B.F. \& Hicks, D.J. (1982) The ecology of leaf life spans. Annual Review of Ecology and Systematics 13, 229259.

Chazdon, R.L. (1988) Sunflecks and their importance to forest understorey plants. Advances in Ecological Research 18, $1-63$.

Evans, J.R. (1989) Photosynthesis and nitrogen relationships in leaves of $\mathrm{C}_{3}$ plants. Oecologia 78, 9-19.

Evans, J.R. (1993) Photosynthetic acclimation and nitrogen partitioning within a lucerne canopy. II Stability through time and comparison with a theoretical optimum. Australian Journal of Plant Physiology 20, 69-82.

Farquhar, G.D., Von Caemmerer, S. \& Berry, J.A. (1980) A biochemical model of photosynthetic $\mathrm{CO}_{2}$ assimilation in leaves of $\mathrm{C}_{3}$ species. Planta $149,78-90$.

Field, C. \& Mooney, H.A. (1986) The photosynthesisnitrogen relationship in wild plants. On the Economy of Plant Form and Function (ed. T.J. Givnish), pp. 25-55. Cambridge University Press, Cambridge, UK.

Friend, A.D. (1991) Use of a model of photosynthesis and leaf microenvironment to predict optimal stomatal conductance and leaf nitrogen partitioning. Plant, Cell and Environment 14, 895-905.

Gleason, H.A. \& Cronquist, A. (1991) Manual of Vascular Plants of Northeastern United States and Adjacent Canada. New York Botanical Garden, New York.

Graves, J.D. (1990) A model of the seasonal pattern of carbon acquisition in two woodland herbs, Mercurialis perennis $\mathrm{L}$. and Geum urbanum L. Oecologia 83, 479-484.

Hanes, B.D. \& Rickwood, D. (1990) Gel Electrophoresis of Proteins. A Practical Approach. IRL Press, Oxford, UK.

Hicks, D.J. \& Chabot, B.F. (1985) Deciduous forests. Physiological Ecology of North American Plant Communities (eds B.F. Chabot \& H.A. Mooney), pp. 257-277. Chapman \& Hall, New York.

Host, G.E. \& Pregitzer, K.S. (1991) Ecological species groups for upland forest ecosystems of northwestern Lower Michigan. Forest Ecology and Management 43, 87-102. 
731

Photosynthetic

characteristics of

deciduous-forest

herbs
Inskeep, W.P. \& Bloom, P.R. (1985) Extinction coefficients of chlorophyll $a$ and $b$ in $N, N$-dimethylformamide and $80 \%$ acetone. Plant Physiology 77, 483-485.

Kamaluddin, M. \& Grace, J. (1992) Photoinhibition and light acclimation in seedlings of Bischofia javanica a tropical forest tree from Asia. Annals of Botany 69, 47-52.

Landhausser, S.M., Stadt, K.J. \& Lieffers, V.J. (1997) Photosynthetic strategies of summergreen and evergreen understory herbs of the boreal mixedwood forest. Oecologia 112, $173-178$.

Mahall, B.E. \& Bormann, F.H. (1978) A quantitative description of the vegetative phenology of herbs in a northern hardwood forest. Botanical Gazette 139, 467-481.

Oberhuber, W. \& Bauer, H. (1991) Photoinhibition of photosynthesis under natural conditions in ivy (Hedera helix $\mathrm{L}$.) growing in an understory of deciduous trees. Planta 185, $545-553$.

Pearcy, R.W. \& Sims, D.A. (1994) Photosynthetic acclimation to changing light environments: scaling from leaf to whole plant. Exploitation of Environmental Heterogeneity by Plants (eds M.M. Caldwell \& R.W. Pearcy), pp. 145174. Academic Press, New York.

Pitelka, L.F. \& Curtis, W.F. (1986) Photosynthetic responses to light in an understory herb, Aster acuminatus. American Journal of Botany 73, 535-540.

Prioul, J.L. \& Chartier, P. (1977) Partitioning of transfer and carboxylation components of intracellular resistance to photosynthetic $\mathrm{CO}_{2}$ fixation: a critical analysis of the methods used. Annals of Botany 41, 789-800.

Reich, P.B., Walters, M.B. \& Ellsworth, D.S. (1992) Leaf lifespan in relation to leaf, plant, and stand characteristics among diverse ecosystems. Ecological Monographs 62, 365-392.

Rothstein, D.E. (1999) Ecophysiology of three deciduous forest herbs: relationships between physiology, life history and ecosystem-level nitrogen cycling. $\mathrm{PhD}$ thesis, University of Michigan, Ann Arbor, MI

Skillman, J.B., Strain, B.R. \& Osmond, C.B. (1996) Contrasting patterns of photosynthetic acclimation and photoinhibition in two evergreen herbs from a winter deciduous forest. Oecologia 107, 446-455.

Sparling, J.H. (1967) Assimilation rates of some woodland herbs in Ontario. Botanical Gazette 128, 160-168.

Taylor, R.J. \& Pearcy, R.W. (1976) Seasonal patterns of the $\mathrm{CO}_{2}$ exchange characteristics of understory plants from a deciduous forest. Canadian Journal of Botany 54, 1094 1103.

Tissue, D.T., Skillman, J.B., McDonald, E.P. \& Strain, B.R. (1995) Photosynthesis and carbon allocation in Tipularia discolor (Orchidaceae), a wintergreen understory herb. American Journal of Botany 82, 1249-1256.

Voss, E.G. (1985) Michigan Flora. University of Michigan, Ann Arbor, MI

Wilkinson, L. (1990) SYSTAT: The System for Statistics. SYSTAT, Evanston, IL.

Yoshie, F. \& Kawano, S. (1986) Seasonal changes in photosynthetic characteristics of Pachysandra terminalis (Buxaceae), an evergreen woodland chamaephyte, in the cool temperate regions of Japan. Oecologia 71, 6-11.

Received 29 January 2001; revised 20 June 2001; accepted 21 June 2001
(C) 2001 British

Ecological Society, Functional Ecology, 15, 722-731 